Research Article

\title{
Mining Failure Response Characteristics of Stope Floor: A Case of Renlou Coal Mine
}

\author{
Jucai Chang, Dong Li $(\mathbb{D}$, and Kai He $\mathbb{D}$ \\ Key Laboratory of Safe and Effective Coal Mining of the Ministry of Education, Anhui University of Science and Technology, \\ Huainan 232001, China \\ Correspondence should be addressed to Dong Li; austerlidong@163.com
}

Received 18 August 2020; Revised 18 September 2020; Accepted 21 September 2020; Published 8 October 2020

Academic Editor: Zhijie Wen

Copyright () 2020 Jucai Chang et al. This is an open access article distributed under the Creative Commons Attribution License, which permits unrestricted use, distribution, and reproduction in any medium, provided the original work is properly cited.

Currently, shallow coal resources are being exhausted gradually, mining depth is continuing to extend downward, and hydrogeological conditions are becoming increasingly complex. Therefore, accurate determination of the failure floor position is necessary to perform multiple-seam mining. In this study, the 7255 working face of the Renlou coal mine is regarded as the research object. Through a comprehensive measurement of ground penetrating radar detection and fixed-point grating optical fibers, the law of floor deformation and failure is analyzed dynamically, and the characteristics of the floor rock deformation response are discussed. The results of on-site monitoring indicate that the mining effect of the working face is greater than that of the tectonic stress. With the advance of the working face, the deformation of the shallow area $(0-8 \mathrm{~m})$ first increases gradually, then increases rapidly, and finally increases gradually again; the middle area $(8-19 \mathrm{~m})$ experiences three stages, from a gentle increase to temporary stability and then a rapid increase; the deep area (19-29 $\mathrm{m}$ ) undergoes three stages, from being stable to increasing and then being stable again. After mining, the floor of the working face can be classified into four areas in the vertical direction: complete failure area $(0-5 \mathrm{~m})$, poor severe influence area $(5-11 \mathrm{~m})$, failure development area $(11-19 \mathrm{~m})$, and elastic deformation area (19-29 m). Mining-induced stresses cause resistance at the interface of different lithologies and weaken the effect of downward propagation. Coal seams and the interface between different lithologies are more prone to deformation. The results can provide a certain reference basis for the advanced exploration scheme of the underlying seam mining under the multiple-seam mining method, as well as provide a new approach for floor failure depth measurement.

\section{Introduction}

As the depth of coal mining continues to extend downward annually, the geological and hydrogeological conditions of coal mines are becoming increasingly complex. Additionally, water burst accidents may occur in the coal seam floor during mining, causing significant economic losses. For example, the geological and hydrogeological types of the Renlou coal mine are extremely complex, and the main water hazards include quaternary loose bed water, coal measure sandstone fracture water, limestone water, and goaf water. In general, a direct water filling phenomenon does not exist in the Taiyuan formation and Ordovician limestone karst aquifer to the mine. However, when a water-flowing subsided column is encountered in shaft engineering, it can directly flow into the mine pit, causing water bursts. In particular, the Ordovician limestone aquifer has a high water pressure, which can easily cause water burst disasters. Therefore, the failure depth and geological conditions under the floor must be detected accurately.

In recent decades, many scholars worldwide have studied the failure depth of floors and the theoretical derivation is relatively mature. Meng et al. established an elastic mechanical model and provided a failure criterion for any point below the floor [1]. According to the elastic theory, Zhang and Wang calculated the additional stress under a floor and drew a stress nephogram to estimate the failure depth [2]. Lu and Yao considered isotropy, deduced the analytical solution of stress, and provided a failure criterion [3]. Sun constructed theoretical models for inclined coal 
seams and analyzed them through an orthogonal design [4]. Based on results of previous theoretical studies, $\mathrm{Hu}$ et al. established a backpropagation neural network model for analysis [5]. In addition to theoretical studies, scholars have conducted auxiliary analyses on failure depth through numerical and indoor physical simulations. Liang et al. conducted theoretical derivations considering the effects of floor confined water and goaf; subsequently, they presented failure criteria for floors and verified them numerically and experimentally $[6,7]$. Meng et al. simulated the failure depth of inclined coal seams with faults [8]. Liu and Liu considered a crack grid and used numerical popular methods to simulate crack propagation [9]. Li et al. used 3DFLAC to simulate the height development of a water-conducted fracture zone and the floor failure depth before and after coal mining [10]. Peng et al. studied the static and dynamic mechanical properties of granite at the buried depth in the laboratory $[11,12]$. In addition, under cyclic loading conditions, the deformation characteristics and failure of sandstone were studied [13]. Wang et al. researched the mechanical properties of rock under nonuniform load through the self-developed acoustic emission [14]. Wen et al. studied the development height of the water-flowing fractured zone through laboratory experiments and numerical simulations [15].

Regardless of theoretical analysis or physical and numerical simulations, for complex undergrounds, not all conditions can be considered. Since the end of the last century, researchers have performed numerous on-site measurement works to measure the accuracy of floor failure depths. Currently, six main methods exist: multipleposition extensometer [16], borehole strain [17, 18], borehole peeping [19], computed tomography electronic imaging [20, 21], ground penetrating radar detection $[22,23]$, and microseismic monitoring [24-26]. Owing to the wider application of optical fibers in the past two years, they have begun to be used in coal mines, e.g., the Brillouin optical time domain reflectometer to measure floor failure depth [27, 28].

To summarize, many methods are available for measuring floor failure depth; however, the measurement accuracy is insufficient. A distributed optical fiber cannot measure floor deformations continuously because of the large deformation of the strata; however, a fixed-point grating optical fiber with double loops can effectively solve this problem. With the increasing depth of coal mines, the resulting complex geology inevitably affects the judgment of measurement results. Current approaches cannot satisfy the accuracy requirements. The research object of this study is the $7{ }_{2} 55$ working face of the Renlou coal mine, which adopts close-distance multiple-seam mining. To mine a new area, an advanced exploration known as "two exploration" must be performed. As such, after mining the underlying $7_{2}$ coal seam, the mining failure depth of the coal seam floor should be determined. Therefore, ground penetrating radar detection and a fixed-point grating optical fiber were used in this study to dynamically monitor the deformation and failure of a coal seam floor, providing reference for the advanced exploration scheme of underlying seam mining.
1.1. Geological Survey. The research object of this study is the $7_{2} 55$ working face of the Renlou coal mine in Suzhou, China. The working face corresponds to a flat-terrain surface, with an average elevation of $25.6 \mathrm{~m}$. It is in the first stage of the south middle-five mining area. The middle section is a working face with a safety pillar under water bodies, and the smallest pillar measures $50.1 \mathrm{~m}$. In the north, it extends to the return airway with an elevation from -332.1 to $-504.5 \mathrm{~m}$. In the south, it extends to the haulage gateway with an elevation from -362.2 to $-537.8 \mathrm{~m}$ and faces the $7_{2} 57$ goaf below. The strike length is $1332 \mathrm{~m}$, dip width is $101-163 \mathrm{~m}$, and area is approximately $181980 \mathrm{~m}^{2}$. The average ground temperature gradient is $0.0312^{\circ} \mathrm{C} / \mathrm{m}$. It must be noted that the underlying $7_{3}$ and $8_{2}$ minable coal seams have not been mined.

The thickness of the $7_{2}$ coal seam is $0.2-9.5 \mathrm{~m}$, with an average of $2.6 \mathrm{~m}$; the seam is relatively stable and has a simple structure. The distance between the $7_{2}$ and $7_{3}$ coal seams in this district is $0-7.0 \mathrm{~m}$, with an average of $4.0 \mathrm{~m}$. The overall trend is to gradually decrease from the middle to the east and west. The immediate roof is gray mudstone containing plant fossils and silty sand; its average thickness is $1.5 \mathrm{~m}$ and its uniaxial compressive strength is $46.83 \mathrm{MPa}$. The main roof is made of fine sandstone with an average thickness of $6.8 \mathrm{~m}$ and a uniaxial compressive strength of 52.48 $\mathrm{MPa}$. The immediate floor comprises mudstone, with an average thickness of $4.0 \mathrm{~m}$ and a uniaxial compressive strength of $41.58 \mathrm{MPa}$; the $7_{3}$ coal seam is located below it. The geological columnar section is shown in Figure 1.

1.2. Estimation of Floor Failure Depth. To design the on-site monitoring scheme, the maximum failure depth of the floor must be estimated in advance. According to regulations and experience [29], the formula to calculate the failure depth of the working face floor is as follows:

$$
h_{\max }=0.0085 H+0.1665 \alpha+0.1079 L-4.3579 \text {, }
$$

where $H$ is the mining depth, $\alpha$ the coal seam dip angle, and $L$ the inclined length of the working face. When $H=418 \mathrm{~m}$, $\alpha=13.4^{\circ}$, and $L=163 \mathrm{~m}$ are used in equation (1), the calculated failure depth is $19.01 \mathrm{~m}$.

According to the slip line theory, the slip line of a coal seam floor rock mass (i.e., the boundary of the plastic zone) comprises three regions: active, transition, and passive zones [24], as shown in Figure 2

$$
h=r_{0} e^{\theta t g \varphi_{0}} \cos \left(\theta+\frac{\varphi_{0}}{2}-\frac{\pi}{4}\right),
$$

where $h$ is the failure depth of the floor heave and $\varphi_{0}$ is the friction angle of the floor heave.

Let $\mathrm{d} h / \mathrm{d} \theta=0$; therefore,

$$
r_{0} e^{\theta t g \varphi_{0}} \cos \left(\theta+\frac{\varphi_{0}}{2}-\frac{\pi}{4}\right) \operatorname{tg} \varphi_{0}-r_{0} e^{\theta t g \varphi_{0}} \sin \left(\theta+\frac{\varphi_{0}}{2}-\frac{\pi}{4}\right)=0 .
$$

In this study, $\theta=\left(\varphi_{0} / 2\right)+(\pi / 4)$ was used for simplification. By substituting equation (2), the maximum failure depth of the floor becomes 


$$
h_{\max }=\frac{x_{a} \cos \varphi_{0}}{2 \cos \left((\pi / 4)+\left(\varphi_{0} / 2\right)\right)} e^{\left[\cos \left(\frac{\pi}{4} \frac{\varphi_{0}}{2}\right)\right] \operatorname{tg} \varphi_{0}},
$$

where $x_{a}$ is the yield zone length, $x_{a}=0.015 \mathrm{H}$, and $\varphi_{0}$ is the internal friction angle of the floor. Using the data of the $7_{2} 55$ working face in equation (4), we obtain $h_{\max }=18.76 \mathrm{~m}$; additionally, the theoretical floor failure depth of the $7_{2} 55$ working face was approximately $19 \mathrm{~m}$.

\section{Onitse Monitoring Technology and Scheme}

To measure the floor failure depth after mining, considering the geological conditions of the site, ground penetrating radar (GPR) detection and fixed-point grating optical fiber measurement were performed to comprehensively monitor the floor failure depth.

2.1. Principle of GPR Detection. GPR is a geophysical detection instrument that uses radio waves with a frequency between $10^{6}$ and $10^{9} \mathrm{~Hz}$ to determine the underground medium. It is mainly composed of an antenna, a transmitter, a receiver, a signal processor, and a terminal device. The transmitting antenna transmits high-frequency short-pulse electromagnetic waves into the ground. When the electromagnetic waves encounter the stratum or target with electrical differences during the propagation, they are reflected and transmitted. The receiving antenna receives the reflected wave signal and digitizes it. The computer records it in the form of a reflected wave.

2.2. GPR Test Scheme. GPR model ltd-2100 was used on-site, and the main frequency of the antenna was $100 \mathrm{MHz}$. During the measurement, the antenna of the GPR was placed on the floor of the return airway and moved forward slowly and uniformly to improve the detection accuracy. An automatic gain and an average permittivity of 5.5 were selected for the detection.

The specific detection area was segmented into two sections. One was in the working face; considering the effect of stress concentration at the corner of the roadway, the detection area was set at approximately $50 \mathrm{~m}$ from the return airway to the working face, and the detection range was approximately $10 \mathrm{~m}$. The other section was in the return airway, starting from the face end to within $100 \mathrm{~m}$ in front of the working face (see Figure 3).

\subsection{Principle of Fixed-Point Grating Optical Fiber} Measurement. The fiber Bragg grating sensor was formed by varying the refractive index of the fiber core to produce small periodic modulations. When the temperature or stress changes, the fiber produces an axial strain. The strain increases the grating period, and the radii of the core and cladding decrease. The refractive index of the fiber is changed by the photoelastic effect, resulting in a shift in the wavelength.

The reflected wavelength $\lambda_{B}$ is related to the grid spacing and the refractive index of the optical fiber. When axial deformation or temperature change occurs in the optical fiber, the grid spacing and refractive index drift and the reflection wavelength shift accordingly [30]:

$$
\lambda_{B}=2 n_{\text {eff }} \Lambda \text {. }
$$

Through laboratory experiments, it was discovered that the strain and temperature exhibited a linear relationship with the center wavelength $\lambda_{B}$ and that they were independent of each other. The correlation formula is shown as [30]

$$
\triangle \lambda_{B}=\alpha_{\varepsilon} \varepsilon+\alpha_{T} \Delta T .
$$

In the formula, $\alpha_{\varepsilon}$ is the strain sensitivity coefficient of the fiber grating, $\alpha_{T}$ the temperature sensitivity coefficient of the fiber grating, $\Delta T$ the temperature change value, and $\varepsilon$ the strain. In this study, the wavelength demodulation accuracy reached $1 \mathrm{pm}$, corresponding to its strain measurement accuracy of approximately $1 \mu \varepsilon$, and the temperature demodulation accuracy was $0.1^{\circ} \mathrm{C}$. By encapsulating the element that can accurately measure the microdeformation into a number of point sensors, the strain of the failure of the floor can be measured.

\subsection{Scheme of Fixed-Point Grating Optical Fiber} Measurement. Combined with the theoretical calculation of the floor failure depth and the site situation, a hole was drilled in the return airway near the coal wall side of the working face. The direction of the hole was vector vertical to the advancing direction of the working face. The distance between the hole position and the working face was approximately $108 \mathrm{~m}$, hole depression angle was $60^{\circ}$, and monitoring borehole length was $55 \mathrm{~m}$. The vertical distance between the hole bottom and the floor was $42.1 \mathrm{~m}$ (see Figure 4(a)).

As shown in Figure 4(b), the monitoring borehole is composed of a grouting pipe, a packaged fixed-point grating, a plastic pipe, a loop wire, and cable ties. The fixed-point optical cable packaged by an ordinary fiber Bragg grating had eight fiber Bragg grating points in series. The distance between the packaged fixed-point gratings was $2 \mathrm{~m}$. An armored wire was used in the middle. The length of each fixed-point optical cable was $16 \mathrm{~m}$, and each section was a loop. If the optical fiber breaks due to excessive displacement, the measurement can be continued through the double loop leads.

The on-site construction can be divided into five steps: drilling construction, connection of the grating optical fiber, movement of the fixed-point fiber toward borehole bottom, drilling grouting, and fiber wire protection (see Figure 5). (1) After the monitoring of drilling was completed, the hole diameter was $91 \mathrm{~mm}$, and the drilling hole was washed and cleaned. An exploratory hole can be created if necessary. (2) Before connecting the fixed-point optical fiber and the plastic pipe, two bundles of communication optical cables measuring $150 \mathrm{~m}$ were connected in series at both ends of the $16 \mathrm{~m}$ fiber Bragg grating. The communication optical fiber cables were connected with a single-mode common jumper. The connection was protected by a thin flexible tube first, followed by 


\begin{tabular}{|c|c|c|c|c|}
\hline $\begin{array}{l}\text { Cumulative } \\
\text { thickness }\end{array}$ & $\begin{array}{c}\text { Layer } \\
\text { thickness }\end{array}$ & $\begin{array}{c}\text { Columnar } \\
1: 500\end{array}$ & Rock & Lithology \\
\hline 34.12 & 9.94 & $\begin{array}{ll}00 & \\
00 & 00 \\
00 & 00\end{array}$ & Medium sandstone & \multirow{5}{*}{$\begin{array}{l}\text { Roof: the main roof is mainly } \\
\text { sandstone with an average } \\
\text { uniaxial compressive strength of } \\
52.48 \mathrm{MPa} \text {, and the immediate } \\
\text { roof is mudstone with an average } \\
\text { uniaxial compressive strength of } \\
46.83 \mathrm{MPa}\end{array}$} \\
\hline 24.18 & 9.18 & $\begin{array}{r}- \\
-- \\
- \\
-\end{array}$ & Mudstone & \\
\hline 15.00 & 6.65 & & Siltstone & \\
\hline 8.35 & 6.84 & & Fine sandstone & \\
\hline \multirow[t]{2}{*}{1.51} & 1.51 & & Mudstone & \\
\hline & 2.60 & & $7_{2}$ coal seam & \multirow{2}{*}{$\begin{array}{l}\text { The } 7_{2} \text { coal seam is black and in a } \\
\text { powder form with a fragment shape } \\
\text { and a glass luster }\end{array}$} \\
\hline 1.27 & 1.27 & - & Mudstone & \\
\hline 3.05 & 1.78 & 0000 & Siltstone & \multirow{13}{*}{$\begin{array}{l}\text { Floor: the floor is mainly } \\
\text { mudstone; the immediate } \\
\text { floor is mudstone and silty } \\
\text { sand, and its uniaxial } \\
\text { compressive strength is } 41.58 \\
\text { MPa }\end{array}$} \\
\hline 3.97 & 0.92 & & Mudstone & \\
\hline 6.69 & 2.72 & & $7_{3}$ coal seam & \\
\hline 9.47 & 2.78 & & Mudstone & \\
\hline 16.96 & 7.49 & & Fine sandstone & \\
\hline 20.28 & 3.32 & & Siltstone & \\
\hline 22.21 & 1.93 & & $8_{2}$ coal seam & \\
\hline 25.59 & 3.38 & & Mudstone & \\
\hline 26.96 & 1.37 & & $8_{3}$ coal seam & \\
\hline 30.84 & 3.88 & \begin{tabular}{|l|}
$-0-0$ \\
$-0-$
\end{tabular} & Mudstone & \\
\hline 34.26 & 3.42 & 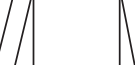 & Sandstone & \\
\hline 39.77 & 5.51 & & Siltstone & \\
\hline 43.96 & 4.19 & & $\begin{array}{l}\text { Aluminous } \\
\text { mudstone }\end{array}$ & \\
\hline
\end{tabular}

Figure 1: Geological columnar section.

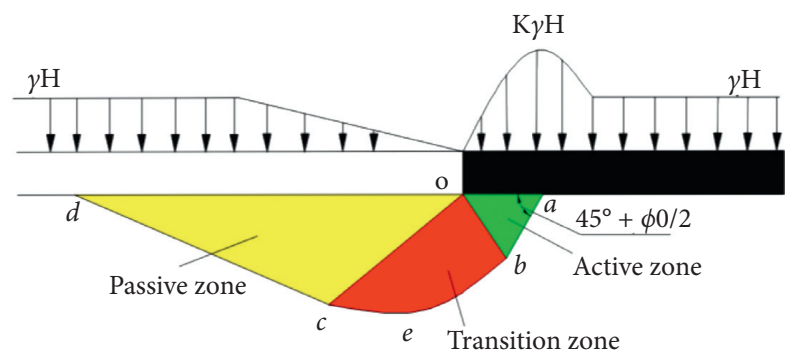

Figure 2: Diagram for calculating maximum failure depth of floor. 


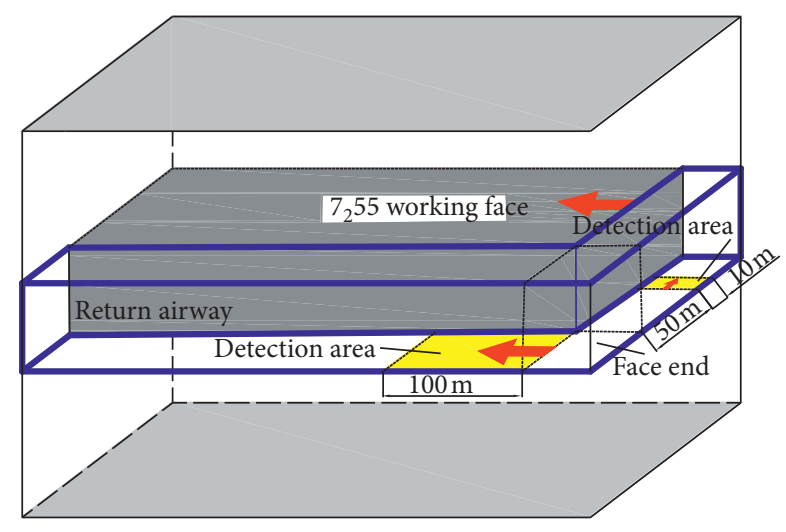

FIgURE 3: Schematic diagram of the detection area.

a thin steel pipe outside. To measure the compression, the fixed-point optical cable was prestretched by $2 \mathrm{~nm}$; it passed the FBG-A03 test for verifying whether the optical fiber was perfectly connected and whether the data were normal. (3) At the bottom of the plastic pipe, the fixed-point fiber Bragg grating and the loop wire were fixed to the plastic pipe using tape; subsequently, the cable was fixed every $1 \mathrm{~m}$. By controlling the plastic pipe along the borehole direction, the fiber optic cable fixed with the plastic pipe can be lowered slowly. Furthermore, the upper and lower segments of the plastic pipe can be connected by a thread, and the remaining fixed-point grating fiber optic cable can be arranged downward successively. (4) After the installation, continuous grouting was performed through the grouting hole, and the grouting method used was reverse grouting. After grouting, hole sealing was performed. (5) The wire was extended to a safe position along the direction away from the working face.

\section{Analysis of Monitoring Results}

3.1. GPR. Based on the detection results of the return airway in the $7_{2} 55$ working face, the background was eliminated and Hilbert transform was performed. Subsequently, seven measuring locations were selected to construct the failure depth curve (see Figure 6). Each illustration shows the detection result within $1 \mathrm{~m}$. The color alternation in the GPR detection result map indicated that the reflected wave changed when the electromagnetic wave passed through different lithologic strata. At the same location and depth, the color was uniform and a straight line was shown, indicating that the strata in the exploration area were relatively uniform and that only a few joints existed. Meanwhile, the color change indicated the existence of geological anomalies. Generally, the floor anomalies of coal seams are broken strata and structural changes of rock mass. In addition, changes in wave velocity in different lithologies vary the color of rock strata.

At $0-10 \mathrm{~m}$ in front of the working face, the color of the GPR result map varied significantly with depth. More abnormal areas of floor rock strata and more floor cracks were observed. At $0-20 \mathrm{~m}$, the amplitude of the GPR detection wave increased, and the reflected wave signal was strong. The roadway floor was affected by the front abutment pressure, and cracks appeared under the floor, which had a high degree of stress concentration. The waveform map shows geologically abnormal areas, and the maximum depth was approximately $16.4 \mathrm{~m}$. At $20-50 \mathrm{~m}$, in front of the working face, the failure scope under the floor reduced gradually. Within $50-88 \mathrm{~m}$ in front of the working face, the detection results of the floor rock strata showed that the integrity of roadway strata improved, and the electromagnetic wave reflection signal was relatively stable. Although geologically abnormal areas caused by cracks or cavities in the rock layer under the floor existed in the roadway floor, they were not obvious. In comparison with the area $0-20 \mathrm{~m}$ and $100 \mathrm{~m}$ in front of the working face, the color of the area above the shallow part of $5.25 \mathrm{~m}$ was darker, indicating that the damage of the shallow floor heave was more serious within $50-80 \mathrm{~m}$.

At $0-5.25 \mathrm{~m}$ below the floor, the stope floor belonged to the complete failure area. At 5.25-16.4 m, the color of the GPR detection result map changed significantly; the color was bright, and the alternation of light and dark was obvious, which was the area affected severely by mining disturbance on the working face floor. At $16.4-18.5 \mathrm{~m}$ below the floor, geologically anomalous areas were still reflected in the GPR detection waveform map, but the waveform fluctuation of each abnormal area was small; hence, those areas were considered as small geological influence areas.

The maximum failure depth of the $7_{2} 55$ working face was approximately $18.5 \mathrm{~m}$, as shown in the GPR detection map (see Figure 7), and the floor had many geologically abnormal areas. These areas were caused by the failure due to mining; however, cracks and local fissures were developed. Within 0-13 $\mathrm{m}$ below the floor, the detection reflection waveform was large, as shown in red in the figure.

3.2. Fixed-Point Fiber Grating. The actual installation hole length was $42 \mathrm{~m}$. The sensor layout number at the bottom of the hole represents Section 3; Sections 1 and 2 are both upward. The specific installation parameters are shown in Table 1.

Based on experiments, it was discovered that the strain sensitivity coefficient of the fiber grating was 0.01 . According to the normal ground temperature gradient $\left(0.03^{\circ} \mathrm{C} / \mathrm{m}\right)$ in the area, the temperature change was approximately $1^{\circ} \mathrm{C}$. Therefore, the effect of temperature change on the fiber was not considered, and the wavelength strain formula was simplified to the following:

$$
\varepsilon=K \cdot \Delta \lambda
$$

In the formula, $K$ is the optical fiber characteristic parameter with a value of 845 and $\Delta \lambda$ is the wavelength change.

Data collection was performed regularly on-site, and then equation (7) was used to calculate the strain. According to the different response characteristics of the borehole optical fiber test data under varying mining progress, the strain distribution law in the monitoring hole was drawn (see Figure 8). Tensile strain is defined as positive, whereas compressive strain is defined as negative.

On the second day, after the fixed-point optical fiber installation was completed, the monitoring hole was approximately $100 \mathrm{~m}$ away from the working face, and the floor 


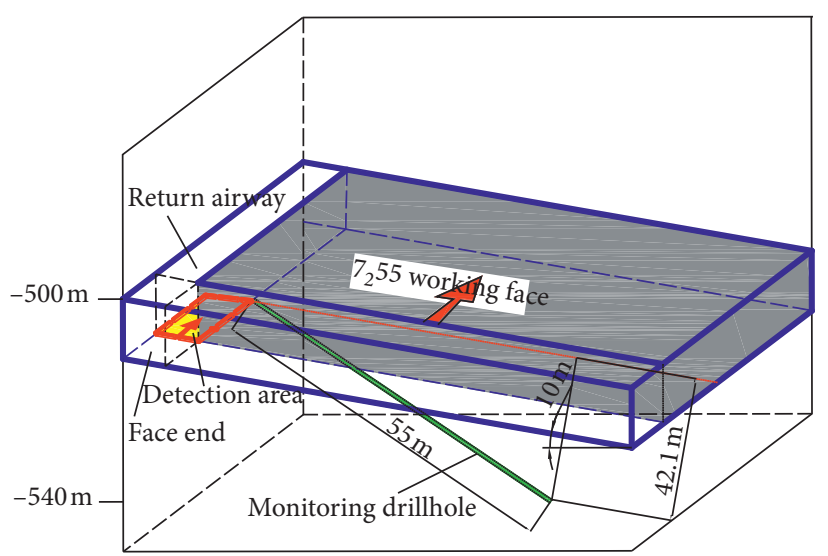

(a)

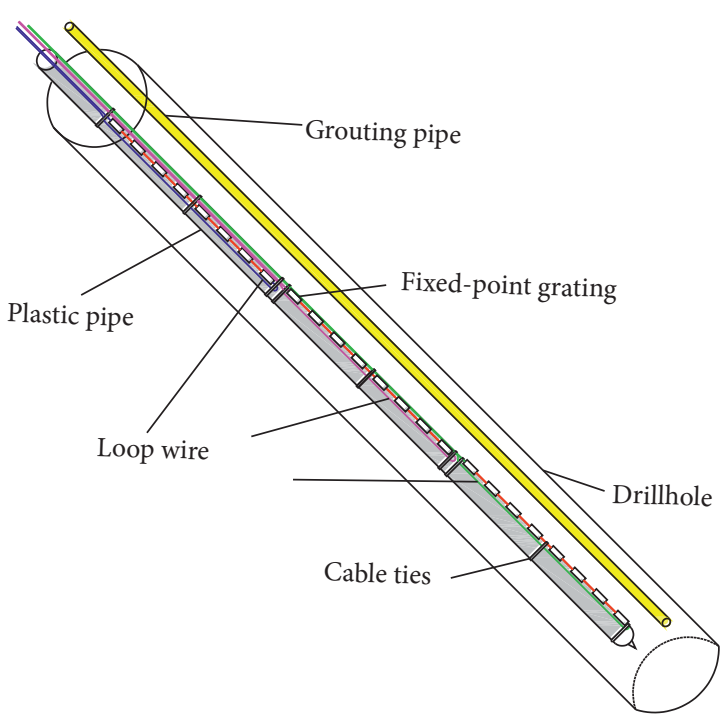

(b)

FIgURE 4: Drilling diagram showing (a) borehole location and (b) monitoring of borehole structure.

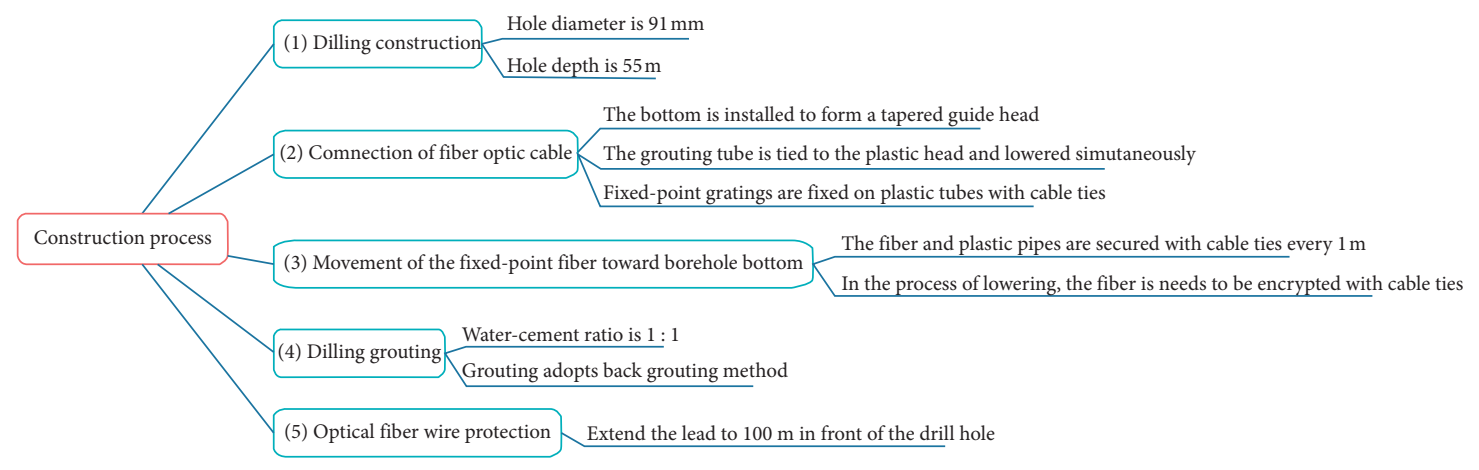

FIGURE 5: Fixed-point optical fiber installation steps.

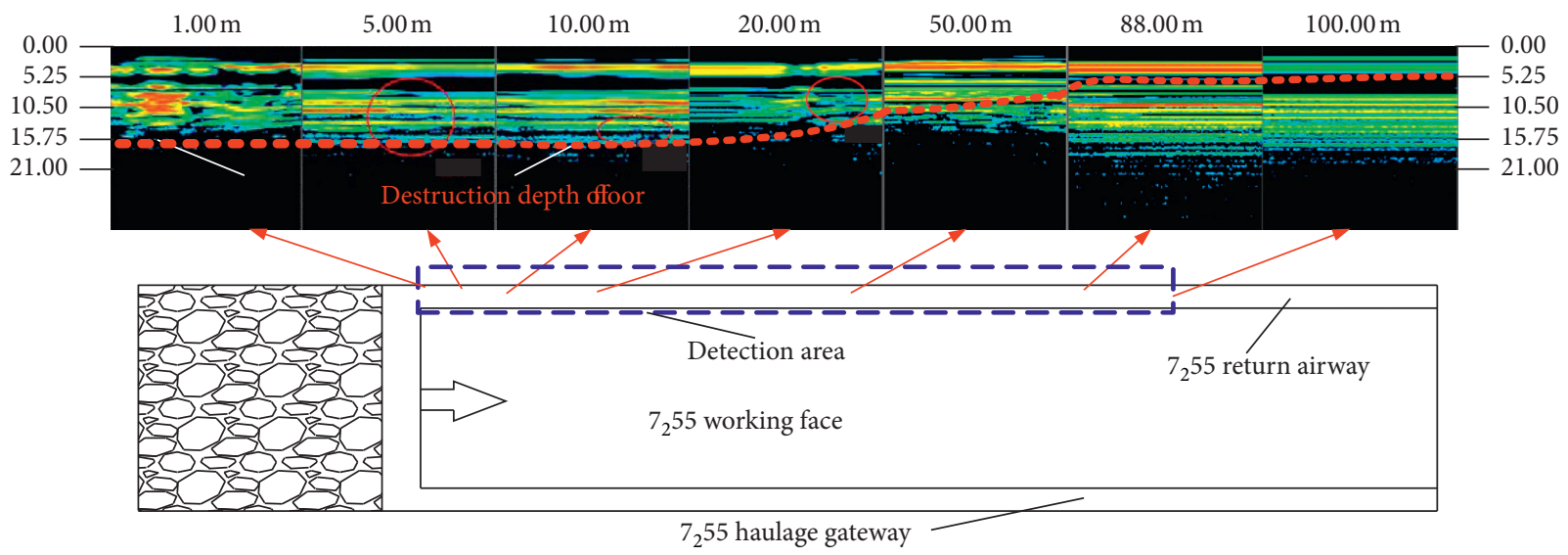

FIGURE 6: GPR detection results in return airway.

was unaffected by mining. Since the hole length measuring $0-5 \mathrm{~m}$ was near the peak stress, as the horizontal stress was being transferred, the floor deformed owing to the horizontal extrusion stress. As the strain increased, the floor broke gradually. Owing to grouting and borehole collapse during installation, strain appeared near the depth of $30 \mathrm{~m}$ in 


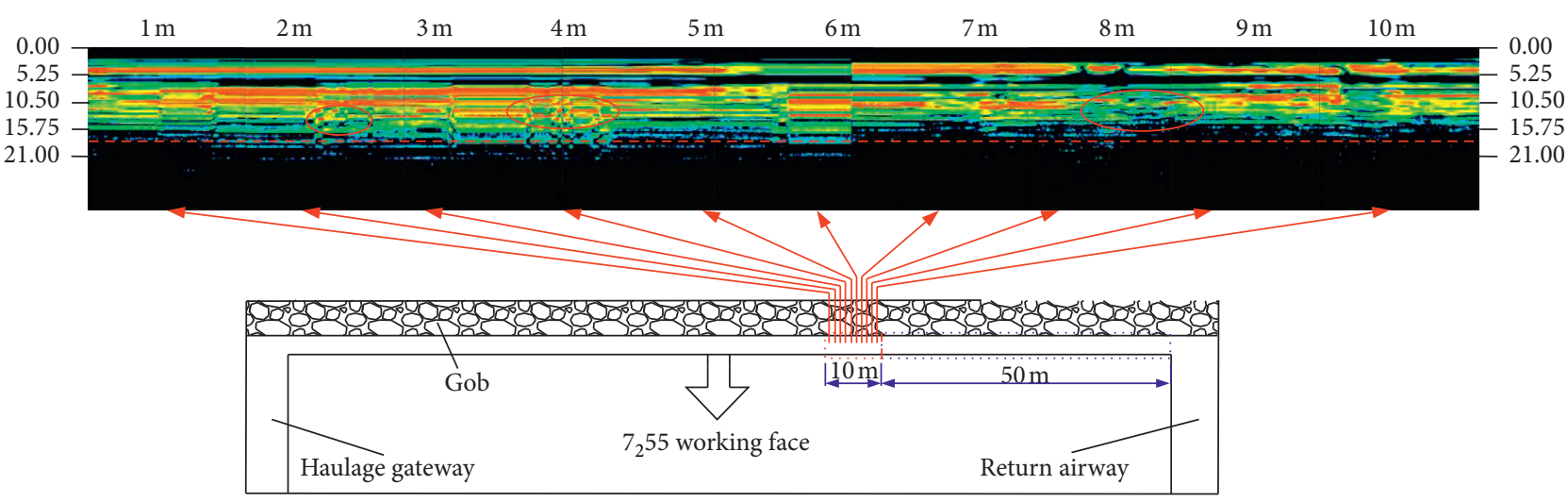

FIGURE 7: GPR detection results in the working face.

TABLE 1: Installation parameters of fixed-point fiber grating position.

\begin{tabular}{|c|c|c|c|c|}
\hline $\begin{array}{l}\text { Section } \\
\text { number }\end{array}$ & $\begin{array}{c}\text { Grating installation } \\
\text { sequence }\end{array}$ & $\begin{array}{c}\text { Hole } \\
\text { length }(\mathrm{m}) \\
\end{array}$ & $\begin{array}{l}\text { Vertical depth } \\
\text { from floor }(\mathrm{m})\end{array}$ & Remarks \\
\hline \multirow{8}{*}{ Section 3} & 1 & 40.50 & 31.01 & \multirow{16}{*}{$\begin{array}{l}\text { Please install Section } 3 \text { of the optical fiber first, and then install } \\
\text { Sections } 2 \text { and } 1 \text { in sequence; next, install the first fixed-point grating } \\
1.5 \mathrm{~m} \text { from the bottom of the hole }\end{array}$} \\
\hline & 2 & 38.50 & 29.48 & \\
\hline & 3 & 36.50 & 27.95 & \\
\hline & 4 & 34.50 & 26.42 & \\
\hline & 5 & 32.50 & 24.89 & \\
\hline & 6 & 30.50 & 23.36 & \\
\hline & 7 & 28.50 & 21.82 & \\
\hline & 8 & 26.50 & 20.29 & \\
\hline \multirow{8}{*}{ Section 2} & 9 & 24.50 & 18.76 & \\
\hline & 10 & 22.50 & 17.23 & \\
\hline & 11 & 20.50 & 15.70 & \\
\hline & 12 & 18.50 & 14.17 & \\
\hline & 13 & 16.50 & 12.64 & \\
\hline & 14 & 14.50 & 11.10 & \\
\hline & 15 & 12.50 & 9.57 & \\
\hline & 16 & 10.50 & 8.04 & \\
\hline \multirow{4}{*}{ Section 1} & 17 & 8.50 & 6.51 & \multirow{4}{*}{ The fixed-point grating closest to the orifice is $2.5 \mathrm{~m}$ away from it } \\
\hline & 18 & 6.50 & 4.98 & \\
\hline & 19 & 4.50 & 3.45 & \\
\hline & 20 & 2.50 & 1.91 & \\
\hline
\end{tabular}

the deep hole, and the strain trend of the fiber grating within the full length of the borehole remained relatively stable.

As shown by the overall change trend, as the working face advanced, the shallow strain increased gradually. The affected area of the floor expanded to the deep part in stages and the shallow tensile strain near the working surface reached 4200 $\mu \varepsilon$. The large changes in stress were mainly concentrated at the depth of $0-20.5 \mathrm{~m}$ in the monitoring hole.

We projected Figure 8 onto the YZ-plane and replaced the $Y$-axis with the vertical depth from the coal seam floor, as shown in Figure 9. From the eight curves (100, 98, 94, 91, 88, 84,76 , and $68 \mathrm{~m}$ away from the working face), it was discovered that, with the advance of the working face, the strain increased albeit insignificantly. When the distance from the working face was greater than $76 \mathrm{~m}$, the influence range was mainly concentrated $0-8.04 \mathrm{~m}$ below the floor, whereas at the distance of $68 \mathrm{~m}$, the maximum influence range of the floor extended to $11.1 \mathrm{~m}$. The working face began to be affected by mining within $68-76 \mathrm{~m}$. This indicates that the floor was beginning to be affected by mining within $68-76 \mathrm{~m}$ from the working face. At 50, 31, and $20 \mathrm{~m}$ from the working face, the range of influence did not expand significantly; however, owing to the advanced support and front abutment pressure, the strain within $0-11.1 \mathrm{~m}$ below the floor increased. In the range of $0-8.04 \mathrm{~m}$, in particular, the maximum tensile strain exceeded $4000 \mu \varepsilon$.

The $x$-axis in Figure 9 was replaced by the drilling depth, corresponding to the spatial relationship of the floor rock (see Figure 10). It was observed that the vertical depths of 6.5 and $8.5 \mathrm{~m}$ were in the $7_{3}$ coal seam. Because the upper and lower layers of the seam were mudstone, their strengths were greater than that of coal, and the strain curve exhibited a peak value at those locations. The vertical depth of $12.5 \mathrm{~m}$, which was at the interface of mudstone and fine sandstone, showed a small 


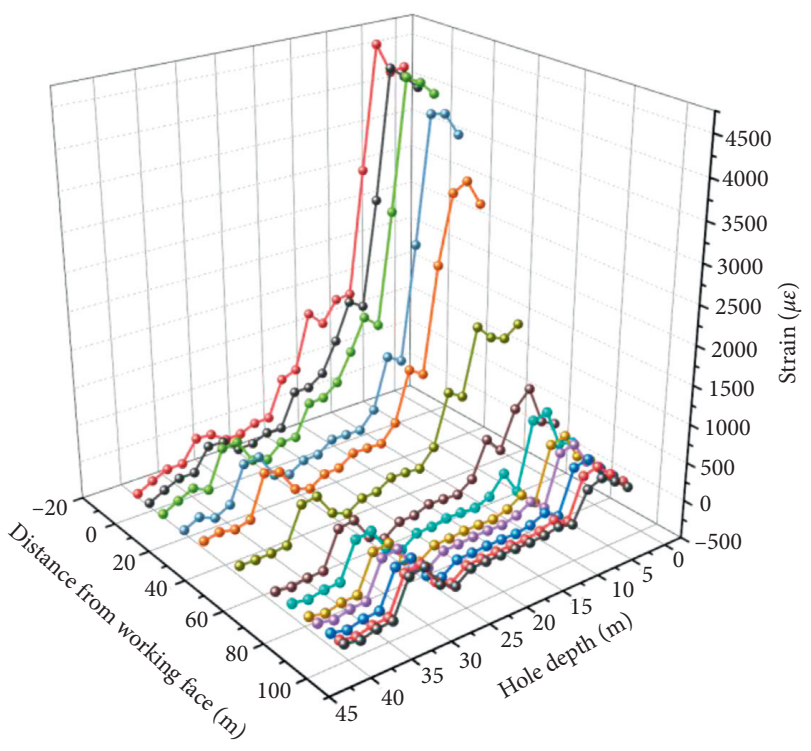

FIGURE 8: Fixed-point fiber grating detection results.

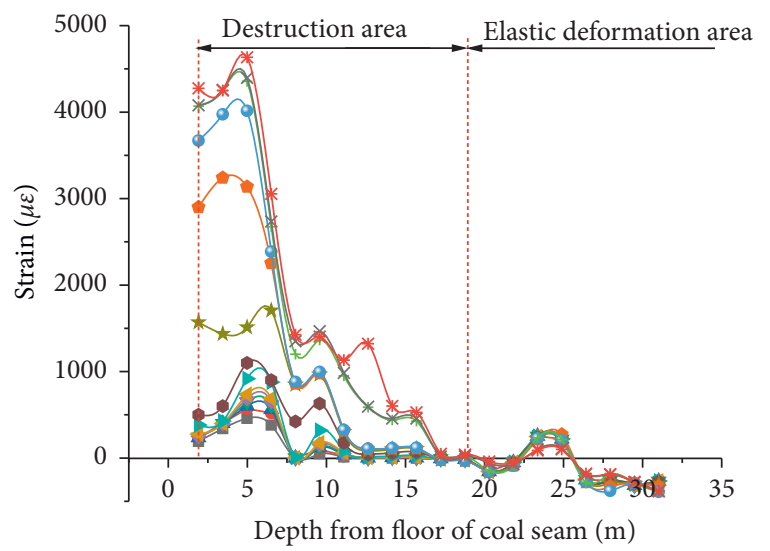

$-100 \mathrm{~m}$ from the working face
$-98 \mathrm{~m}$ from the working face
$-99 \mathrm{~m}$ from the working face
$--88 \mathrm{~m}$ from the working face
$--76 \mathrm{~m}$ from the working face
$-\quad 68 \mathrm{~m}$ from the working face
$--31 \mathrm{~m}$ from the working face
$--20 \mathrm{~m}$ from the working face
$-8 \mathrm{~m}$ from the working face
$-\leftarrow 0 \mathrm{~m}$ from the working face
$*-7 \mathrm{~m}$ from the working face

FIGURE 9: Strain variation curve of the floor at different distances from the working face.

peak as well. When the distance from the working face exceeded $8 \mathrm{~m}$, the stress propagating downward was blocked at the interface of mudstone and fine sandstone below the coal seam floor (at $9.47 \mathrm{~m}$ ). From 8 to $-7 \mathrm{~m}$ away from the working

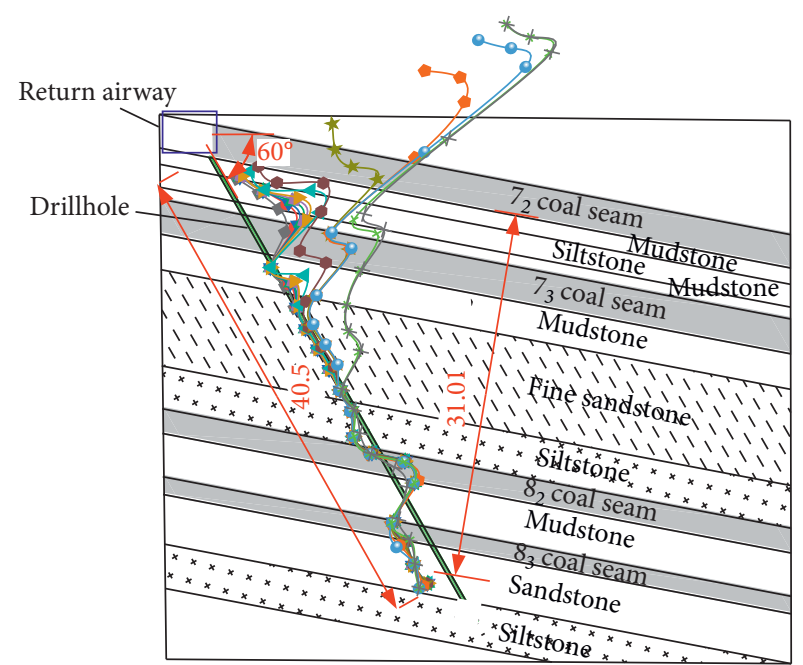

Figure 10: Spatial relationship between fixed-point grating and rock stratum.

face, the downward propagation of stress on the interface of fine sandstone and siltstone below the coal seam floor (at $16.96 \mathrm{~m})$ was hindered.

The data in Figure 8 were projected onto the XZ-plane, and the strain of each vertical depth was connected with a curve and drawn, as shown in Figure 11(a). To better observe the strain change of the floor below $8 \mathrm{~m}$ in vertical depth, a local magnification was performed (see Figure 11(b)).

The stresses of $1.91,4.98$, and $6.51 \mathrm{~m}$ vertical depth curves increased, and the increasing speed could be categorized into three stages: $-7-20 \mathrm{~m}, 20-76 \mathrm{~m}$, and $76-100 \mathrm{~m}$. Meanwhile, the vertical depths of 8.04 and $9.57 \mathrm{~m}$ were classified into four stages, with a transient stable state in the range of $20-50 \mathrm{~m}$. When the vertical depth was 11.1, 12.64, 14.17 , and $15.7 \mathrm{~m}$, the strain increase range was insignificant at $20-76 \mathrm{~m}$ from the working face. However, at $20 \mathrm{~m}$ away from the working face, the strain increased significantly owing to the effect of the front abutment pressure. The vertical depths of 17.23 and $18.76 \mathrm{~m}$ were affected by the transformation of tensile and compressive strains, indicating that the stress changes near this range was due to mining. The vertical depth was $20.29-31.01 \mathrm{~m}$, and the strain was always compressive. In the range of $20.29-27.95 \mathrm{~m}$, the compressive strain decreased. Therefore, the maximum failure depth of the $7 \mathrm{~m}$ floor after mining was $18.76 \mathrm{~m}$, and the vertical depth of $18.76-29.48 \mathrm{~m}$ represented the elastic deformation area.

\section{Discussion}

Because of mining, the stress transferred downward gradually, the fixed-point grating and the surrounding rock of the borehole exhibited synchronous deformation response characteristics, and the deformation and failure showed complexity and variability. Owing to the tectonic stress under the floor, the strain increased from 76 to $100 \mathrm{~m}$ from the working face. When approaching the working face, the strain increased gradually owing to mining stress. The response 


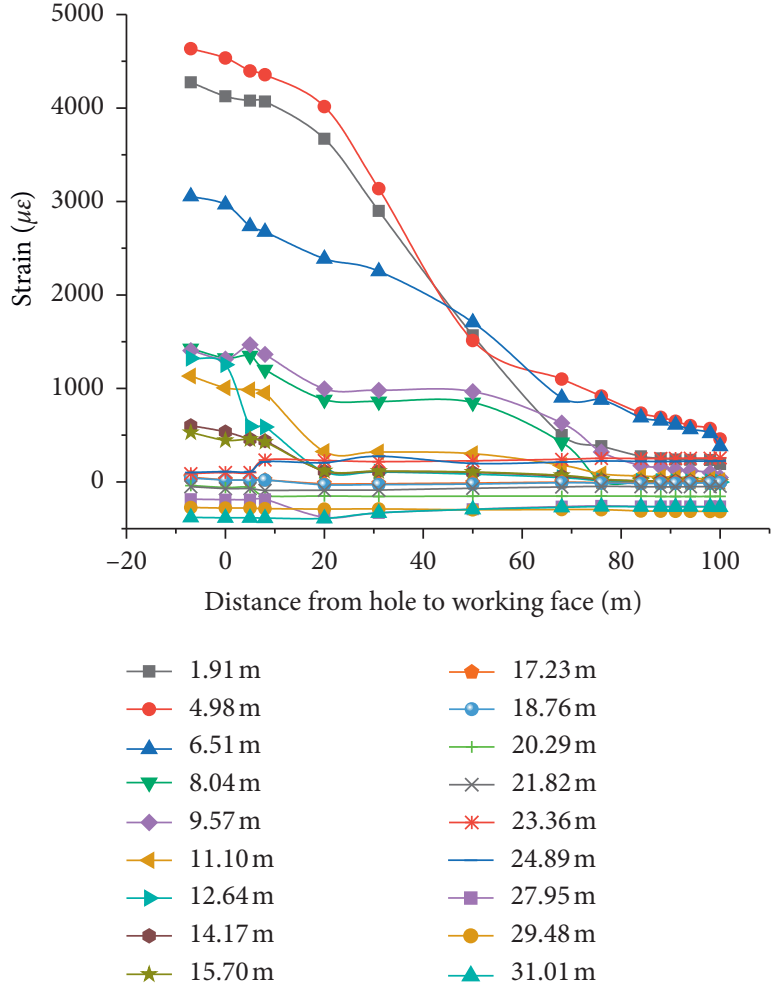

(a)

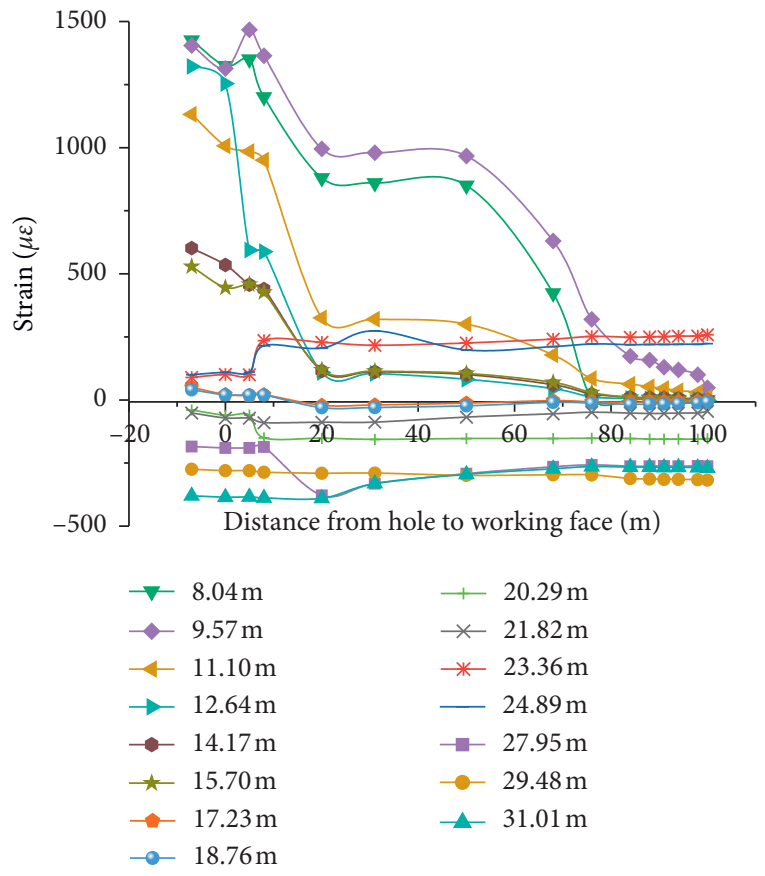

(b)

FIGURE 11: Strain curve of different floor vertical depths. Vertical depth was (a) $1.91-31.01 \mathrm{~m}$ and (b) $8.04-31.04 \mathrm{~m}$.

characteristics of strata affected by mining in different lithologies differed. The strain of strata with poor lithology was greater than that of strata with good lithology, and it was more obvious in the $7_{3}$ coal seam near the floor. As the $8_{2}$ coal seam and $8_{3}$ coal seam were distant from the floor, they were less affected by mining, and the compressive strain reduced significantly near the working face. The interface in different lithologies of strata stress propagation was blocked, and the strain at this interface differed from those in the rocks on both sides. For example, the strain at the interface between mudstone and fine sandstone at a vertical depth of $9.57 \mathrm{~m}$ was greater than that at nearby measuring points. The strain at the interface between fine sandstone and siltstone at a vertical depth of $17.23 \mathrm{~m}$ varied in tension and compression. It was observed that the weak lithology and the position of the interface were more prone to deformation.

Combined with the monitoring results of the GPR and fixed-point grating optical fiber, in the vertical direction of the 7255 working face, the influence range of floor failure was $0-19 \mathrm{~m}$, complete failure area was $0-5 \mathrm{~m}$ below the working face floor, poor severe influence area was $5-11 \mathrm{~m}$, failure development area was 11-19 m, and elastic deformation area was $19-29 \mathrm{~m}$.

\section{Conclusion}

In this study, the floor damage depth of the 7255 working face was first estimated through theoretical analysis. Additionally, combining the site conditions to design the exploration plan of the GPR and fixed-point grating optical fiber, we analyzed the dynamic deformation and failure law of the floor. Combined with the lithology of the floor rocks, the following conclusions were obtained:

(1) Under the effect of tectonic stress, the stress of the floor increased gradually. When approaching the working face, the deformation speed was initially high and then decreased. The main part of the floor exhibited compressive strain, and a small part exhibited tensile strain. The 73 coal seam with weak lithology and its interface were easier to deform, and the interface of different lithologies could resist the downward transmission of rock deformation to a certain extent.

(2) Along the vertical direction, according to the floor deformation and fracture development degree, the floor failure of the 7255 working face was categorized into four areas: complete failure area $(0-5 \mathrm{~m})$, poor severe influence area $(5-11 \mathrm{~m})$, failure development area $(11-19 \mathrm{~m})$, and elastic deformation area (19-29 m).

(3) Along the strike direction, affected by the lithology and joints between the strata, the deformation velocity of the floor from the working face was categorized into three stages:-7-20 m, $20-76 \mathrm{~m}$, and $76-100 \mathrm{~m}$ in the shallow and middle parts and $-7-8 \mathrm{~m}, 8-20 \mathrm{~m}$, and $20-100 \mathrm{~m}$ in the deep part. However, the deformation speeds in the three stages 
differed. The shallow part demonstrated a gradual to rapid increase, followed by a gentler trend; the middle part demonstrated a gradual increase to a temporary stability, followed by a rapid increase; the deep part was stable at first, followed by a rapid increase, and then returned to being stable.

\section{Data Availability}

The data used to support the findings of this study are available from the corresponding author upon request.

\section{Conflicts of Interest}

The authors declare that there are no conflicts of interest regarding the publication of this paper.

\section{Acknowledgments}

This work was supported by the National Natural Science Foundation of China (no. 51774009), Key Research and Development Program of Anhui Province (no. 202004a07020045), and the Natural Science Foundation of Anhui Province (2008085QE226).

\section{References}

[1] X. R. Meng, C. H. Xu, Z. N. Gao, and X. Q. Wang, "Stress distribution and damage mechanism of mining floor," Journal of China Coal Society, vol. 35, no. 11, pp. 1832-1836, 2010.

[2] H. L. Zhang and L. G. Wang, "Computation of mining induced floor additional stress and its application," Journal of Mining and Safety Engineering, vol. 28, no. 2, pp. 288-293, 2011.

[3] H. F. Lu and D. X. Yao, "Stress distribution and failure depths of layered rock mass of mining floor," Chinese Journal of Rock Mechanics and Engineering, vol. 33, no. 10, pp. 2030-2039, 2014.

[4] J. Sun and X. Miao, "Water-isolating capacity of an inclined coal seam floor based on the theory of water-resistant key strata," Mine Water and the Environment, vol. 36, no. 2, pp. 310-322, 2017.

[5] Y. B. Hu, W. Li, and Q. Wang, "Study on failure depth of coal seam floor in deep mining," Environmental Earth Sciences,", vol. 78, no. 24, p. 697, 2019.

[6] Z. Liang, W. Song, and W. Liu, "Theoretical models for simulating the failure range and stability of inclined floor strata induced by mining and hydraulic pressure," International Journal of Rock Mechanics and Mining Sciences, vol. 132, Article ID 104382, 2020.

[7] W. C. Song, Z. Z. Liang, W. T. Liu, and C. B. Zhao, "Theoretical analysis and experimental investigation on failure characteristics and stability of stope floors," Chinese Journal of Rock Mechanics and Engineering, vol. 38, no. 11, pp. 220822218, 2019.

[8] X. Meng, W. Liu, J. Zhao, and X. Ding, "In situ investigation and numerical simulation of the failure depth of an inclined coal seam floor: a case study," Mine Water and the Environment, vol. 38, no. 3, pp. 686-694, 2019.

[9] Q. S. Liu and X. W. Liu, "Research on critical problem for fracture network propagation and evolution with multifield coupling of fractured rock mass," Rock and Soil Mechanics, vol. 35, no. 2, pp. 305-320, 2014.

[10] A. Li, Q. Ma, and Y. Q. Lian, "Numerical simulation and experimental study on floor failure mechanism of typical working face in thick coal seam in Chenghe mining area of Weibei, China," Environmental Earth Sciences, vol. 79, no. 5, pp. 1-22, 2020.

[11] K. Peng, Z. P. Liu, and Q. L. Zou, "Static and dynamic mechanical properties of granite from various burial depths," Rock Mechanics and Rock Engineering, vol. 52, no. 10, pp. 3545-3566, 2019.

[12] K. Peng, Z. Liu, Q. Zou, Q. Wu, and J. Zhou, "Mechanical property of granite from different buried depths under uniaxial compression and dynamic impact: an energy-based investigation," Powder Technology, vol. 362, pp. 729-744, 2020.

[13] P. Kang, J. Q. Zhou, and Q. L. Zou, "Deformation characteristics and failure modes of sandstones under discontinuous multi-level cyclic loads," Powder Technology, vol. 373, pp. 599-613, 2020.

[14] X. Wang, Z. Wen, Y. Jiang, and H. Huang, "Experimental study on mechanical and acoustic emission characteristics of rock-like material under non-uniformly distributed loads," Rock Mechanics and Rock Engineering, vol. 51, no. 3, pp. 729-745, 2018.

[15] Z. J. Wen, S. L. Jing, and L. Tian, "Study of the fracture law of overlying strata under water based on the flow-stress-damage model," Geofluids, vol. 30, no. 2, pp. 207-215, 2020.

[16] H. F. Duan, "Analysis on failure features and failure depth of coal seam floor during mining process," Coal Science and Technology, vol. 42, no. 5, pp. 17-20, 2014.

[17] S. Y. Zhu, Z. Q. Jiang, K. J. Zhou, G. Q. Peng, and C. W. Yang, "The characteristics of deformation and failure of coal seam floor due to mining in Xinmi coal field in China," Bulletin of Engineering Geology and the Environment, vol. 73, no. 4, pp. 1151-1163, 2020.

[18] S. Y. Zhu, Z. Q. Jiang, D. T. Cao, Q. Sun, and C. W. Yang, "Restriction function of lithology and its composite structure to deformation and failure of mining coal seam floor," Natural Hazards, vol. 68, no. 2, pp. 483-495, 2013.

[19] L. Zhang, W. Wang, and H. Z. Tang, "The application of the combination of high-density electrical method and electromagnetic ct to detect granite spherical weathering body," Chinese Journal of Engineering Geophysics, vol. 12, no. 1, pp. 40-44, 2015.

[20] S. H. Yang, X. R Meng, and G. M Zhao, "Application of CT technology in floor failure law detection," Coal Technology, vol. 33, no. 7, pp. 81-83, 2014.

[21] X. Xu, S. Peng, and F. Yang, "Development of a ground penetrating radar system for large-depth disaster detection in coal mine," Journal of Applied Geophysics, vol. 158, pp. 41-47, 2018.

[22] M. Tian, L. Han, Q. Meng, Y. Jin, and L. Meng, "In situ investigation of the excavation-loose zone in surrounding rocks from mining complex coal seams," Journal of Applied Geophysics, vol. 168, pp. 90-100, 2019.

[23] T. H. Ma, C. A. Tang, L. X. Tang, W. D. Zhang, and L. Wang, "Mechanism of rock burst forcasting based on micro-seismic monitoring technology," Chinese Journal of Rock Mechanics and Engineering, vol. 35, no. 3, pp. 470-483, 2016.

[24] F. Z. Yuan, K. Ma, D. Y. Zhang, Z. W. Wang, and X. Y. Sun, "Preparation mechanism of water inrush channels in bottom floor of Dongjiahe Coal Mine based on microseismic 
monitoring," Journal of China Coal Society, vol. 44, no. 6, pp. 1846-1856, 2019.

[25] F. X. Jiang, G. X. Ye, C. W. Wang, D. Y. Zhang, and Y. Q. Guan, "Application of high-precision microseismic monitoring technique to water inrush monitoring in coal mine," Chinese Journal of Rock Mechanics and Engineering, vol. 27, no. 9, pp. 1932-1938, 2008.

[26] P. S. Zhang, D. Zhang, B. Y. Sun, B. Shi, and S. A. Xu, "Optical fiber monitoring technology for evolution characteristic of rock stratum deformation and failure in space of mining field," Journal of Engineering Geology, vol. 27, no. 2, pp. 260-266, 2019.

[27] W. Zhou, P. Zhang, R. Wu, and X. Hu, "Dynamic monitoring the deformation and failure of extra-thick coal seam floor in deep mining," Journal of Applied Geophysics, vol. 163, pp. 132-138, 2019.

[28] S. Gu, A. Li, and J. Wang, "Theoretical analysis and Numerical Simulation Study on failure depth of coal seams floor caused by mining under pressure," in Proceedings of the International Conference on Multimedia Technology, pp. 1367-1372, Hangzhou, China, July 2011.

[29] J. C. Zhang and T. Q. Liu, "Discussion on the depth and distribution characteristics of the fracture zone caused by coal seam floor mining," Journal of China Coal Society, vol. 15, no. 2, pp. 46-55, 1990.

[30] L. B. Yuan and F. Ansari, "Fiber-optic Bragg grating principle and its applications (I) - fiber-optic grating principle," Optical Communication Technology, vol. 22, no. 1, pp. 70-78, 1998. 